\title{
Outcome of Depression and Anxiety After War: A Prospective Epidemiologic Study of Children and Adolescents
}

\author{
Elie G. Karam, ${ }^{1,2,3}$ John Fayyad, ${ }^{1,2,3}$ Aimee N. Karam, ${ }^{1,2,3}$ Nadine Melhem, ${ }^{4}$ Zeina Mneimneh, ${ }^{3,5}$ \\ Hani Dimassi, ${ }^{6}$ and Caroline Cordahi Tabet ${ }^{1,2,3}$ \\ ${ }^{1}$ Department of Psychiatry and Clinical Psychology, Faculty of Medicine, Balamand University, Beirut, Lebanon \\ ${ }^{2}$ Department of Psychiatry and Clinical Psychology, St George Hospital University Medical Center, Beirut, Lebanon \\ ${ }^{3}$ Institute for Development Research Advocacy and Applied Care (IDRAAC), Beirut, Lebanon \\ ${ }^{4}$ Western Psychiatric Institute and Clinic, University of Pittsburgh, Pittsburgh, Pennsylvania, USA \\ ${ }^{5}$ Survey Methodology Program, Institute for Social Research, University of Michigan, Ann Arbor, Michigan, USA \\ ${ }^{6}$ School of Pharmacy, Lebanese American University, Byblos, Lebanon
}

\begin{abstract}
Prospective studies of children exposed to war have not investigated disorders other than posttraumatic stress disorder (PTSD) and have methodological limitations. From a stratified random sample of 386 children and adolescents who had been interviewed 3 weeks after war exposure (Phase 1) a random subsample $(N=143)$ was interviewed a year later (Phase 2). PTSD, major depressive disorder (MDD), separation anxiety disorder (SAD), overanxious disorder (OAD), and psychosocial stressors were assessed using structured interviews administered to both children and adolescents and their parents. The prevalence of disorders among the 143 at Phase 1 was MDD $25.9 \%$, SAD $16.1 \%$, OAD 28.0\%, and PTSD 26.0\%, with 44.1\% having any disorder. At Phase 2 the prevalence was MDD, 5.6\%; SAD, $4.2 \%$; $\mathrm{OAD}, 0 \%$; and PTSD, 1.4\%, with 9.2\% having any disorder. Occurrence of disorders at Phase 1 was associated with older age, prewar disorders, financial problems, fear of being beaten, and witnessing any war event (ORs ranged from 2.5 to 28.6). Persistence of disorders to Phase 2 was associated with prewar disorders $(O R=6.0)$ and witnessing any war event $(O R=14.3)$. There are implications for detection of at-risk cases following wars by screening for adolescents exposed to family violence, those with prewar disorders, and those who directly witnessed war events to target them for specific interventions.
\end{abstract}

Mental health outcomes of children and adolescents exposed to war have received little attention in comparison to outcomes after natural disasters or disasters made by man. Many prospective studies of children and adolescents exposed to traumatic events have appeared in the literature in the last 15 years investigating posttraumatic stress disorder (PTSD) and depression symptoms following natural disasters or disasters made by man (Bolton et al., 2004; Goenjian et al., 2004; Green et al., 1994; Jensen, Dyb, \& Nygaard, 2009; La Greca, Silverman, Vernberg, \& Prinstein, 1996; Mcfarlane, \& Van Hooff, 2009; Mirza, Bhadrinath, Goodyer, \& Gilmour, 1998;

This work has been supported by IDRAAC, the Lebanese Ministry of Interior, UNICEF, the Dutch Foreign Ministry, the Hariri Foundation, the Lebanese Research Council, and the Lebanese Ministry of Education.

Correspondence concerning this article should be addressed to Elie G. Karam, St. George Hospital University Medical Center, IDRAAC Second Floor, Room 208-209, P.O. Box: 166227, Ashrafieh, Beirut, Lebanon 1100 2110. E-mail: egkaram@idraac.org

Copyright (c) 2014 International Society for Traumatic Stress Studies. View this article online at wileyonlinelibrary.com

DOI: $10.1002 /$ jts. 21895
Shaw, Applegate, \& Schorr, 1998) indicating that initial levels of symptoms abate over time in most participants.

Although many studies used convenience samples of refugee children in Western countries (Lustig et al., 2004) only a few followed children or adolescents exposed to war within their own communities in their countries of origin. These studies mostly investigated PTSD as the only diagnosis of interest, finding that rates of PTSD symptoms after war exposure decrease with time (Dyregrov, Gjestad, \& Raundalen, 2002; Hadi, Labre, \& Spitzer, 2006; Kuterovac-Jagodic, 2003; Laor, Wolmer, \& Cohen, 2001; Schwarzwald, Weisenberg, Solomon, \& Waysman, 1994; Thabet \& Vostanis, 2000).

Information from parents, however, was not collected except for preschoolers (Laor et al., 2001) or via rating scales in one study (Thabet \& Vostanis, 2000). None of the studies used structured interviews in their design and none measured prewar disorders. Moreover, given the heterogeneity of war events, it is important to specify whether children actually witnessed these events directly; for example, a child's home may get destroyed during war, but the impact of this traumatic event would be far greater if the child was there at the time of destruction. Prospective studies of children exposed to war so far have not addressed the issue of direct witnessing of events except for one 
study which reported that eyewitness exposure was associated with a lower likelihood of recovery from PTSD 30 months later (Kuterovac-Jagodic, 2003).

Southern Lebanon had been the scene of war for many decades and in 1996, Israel conducted a major military operation in the south and southwest Bekaa regions. Families in their homes or in shelters were exposed to shelling and bombardment by tanks, airplanes, and warships. This operation lasted for 15 days resulting in hundreds of fatalities, thousands of casualties, substantial destruction of property, and displacement of entire communities.

The Institute for Development of Research, Advocacy and Applied Care (IDRAAC) launched a three-pronged program immediately after ceasefire. The first component consisted of a controlled classroom-based intervention (Karam et al., 2008). The second was a child care program for war orphans who lost their parents during the bombarding of the UN shelter at Qana, a village in South Lebanon (Cordahi et al., 2002).

In this article, we report on the third program to examine the outcome of a representative cohort of children and adolescents who were exposed to war 1 year after their initial evaluation by determining the prevalence of depression and anxiety disorders as well as the effect of war exposure, prewar disorders, and psychosocial factors by using structured interviews with both children and their parents. We hypothesized that disorders were likely to persist in children who had witnessed war events, had prewar disorders, and had high levels of psychosocial stressors other than war. A prospective study was conducted with a baseline assessment in May 1996, 3 weeks following the cease-fire (Phase 1) and a follow-up evaluation 1 year later, in May 1997 (Phase 2).

\section{Method}

\section{Participants}

A stratified random sample of 386 students had been drawn from the population of all students $(45,000)$ registered in all public and private schools in South Lebanon and Southwest Bekaa. The sample was selected from 25 schools according to region, size of school, and educational level. Within each school, classes were randomly selected, and within each classroom students were randomly selected as well.

Children 12 years or older had been oversampled because there were twice as many students enrolled in Grades 1-5 than in Grades 6-9. Students in Grades 10-12 were excluded as some were older than 20 , an age higher than intended for this study. Here all subjects 12 years or younger will be referred to as children and those 13 years or older will be referred to adolescents.

In Phase 2, due to resource limitations, a subsample of 143 students out of the 386 subjects was randomly selected for assessment 1 year later in May 1997; this comprises the study sample.
Table 1

Frequency of Exposure to War Events for Phase 2 Participants

\begin{tabular}{|c|c|c|c|c|}
\hline \multirow[b]{3}{*}{ War event } & \multicolumn{4}{|c|}{ Victim } \\
\hline & \multicolumn{2}{|c|}{$\begin{array}{c}\text { Very close } \\
\text { person }\end{array}$} & \multicolumn{2}{|c|}{ Self } \\
\hline & $n$ & $\%$ & $n$ & $\%$ \\
\hline \multicolumn{5}{|l|}{ Damage to house } \\
\hline None & 117 & 81.8 & 110 & 76.9 \\
\hline Partial & 18 & 12.6 & 32 & 22.4 \\
\hline Complete & 8 & 5.6 & 1 & 0.7 \\
\hline \multicolumn{5}{|c|}{ Witnessing house damage } \\
\hline Told & 18 & 69.2 & 21 & 63.6 \\
\hline Saw in person & 8 & 30.8 & 12 & 36.4 \\
\hline \multicolumn{5}{|l|}{ Physical injury } \\
\hline None & 130 & 90.9 & 143 & 100.0 \\
\hline Nonfatal & 6 & 4.2 & - & - \\
\hline Fatal & 7 & 4.9 & - & - \\
\hline \multicolumn{5}{|c|}{ Witnessing physical injury } \\
\hline Told & 9 & 69.2 & - & - \\
\hline Saw in person & 4 & 30.8 & - & - \\
\hline
\end{tabular}

Note. $N=143$

The students at Phase 2 had a mean age of 11.5 years, $S D=3.3$ years at Phase 1 , equally divided between males and females. There were no statistically significant differences between the subsample at Phase 2 and those who were not followed up with respect to age, sex, prewar disorders, psychosocial stressors, and war exposure (data available upon request).

Approximately one in four students' homes were damaged during the war and $18 \%$ had a close person whose house was damaged. Among those with damage to their own homes or those of a close person, about one third actually witnessed this damage taking place. None of the participants sampled in this study were physically injured during the war, but $9.1 \%$ knew a close person who was injured. Among these participants, injuries were witnessed by $30.8 \%$. Details of exposure are presented in Table 1.

All participants reported at least one of the psychosocial stressors at Phase 1. Having been seriously ill was endorsed by $32.9 \%$, having a chronic medical nonpsychiatric illness by $18.9 \%$, family quarrels by $42.0 \%$, financial problems by $49.7 \%$, bereavement by $39.2 \%$, fear of being hurt by someone by $39.9 \%$, having been severely beaten by someone by $29.4 \%$, and a family member severely beaten by $23.1 \%$.

\section{Measures}

The Diagnostic Interview for Children and Adolescents Revised (DICA-R; Welner, Reich, Herjanic, Jung, \& Amado, 1987), was translated by IDRAAC to Arabic in its three versions (child, adolescent, and parent). Back-translation was done by an independent translator followed by consensus meetings 
and pilot field testing. The final form was adopted after another round of consensus meetings to resolve differences if any were still present. The Arabic DICA-R has been successfully used in another study evaluating a classroom-based intervention (Karam et al., 2008). The diagnostic entities used were major depressive disorder (MDD), separation anxiety disorder (SAD), PTSD, and overanxious disorder (OAD). The episode duration for each of these disorders was as per the Diagnostic and Statistical Manual of Mental Disorders (3rd ed., rev.; DSMIII-R; American Psychiatric Association, 1987) MDD 2 weeks, SAD 2 weeks, PTSD 1 month, and OAD 6 months. The time frame for these diagnoses at the baseline assessment was current and prewar. The stressors of having been seriously ill, ever having a chronic medical nonpsychiatric illness, bereavement, having been severely beaten by someone, and a family member severely beaten had a time frame of "ever" occurring prior to interview at Phase 1 . The stressors of family quarrels, financial problems, and fear of being hurt by someone had a time frame of "currently" being experienced at Phase 1. In Phase 2, current MDD, SAD, PTSD, and OAD were measured by the DICA-R administered to children, adolescents, and parents.

Based on findings from epidemiologic studies of childhood psychiatric disorders (Jensen et al., 1999) and the standard for structured interviews of children, adolescents, and their parents, a symptom was considered present if it was endorsed in the DICA-R by either child or parent. Psychosocial stressors were considered present if endorsed by either child or parent. Diagnoses were established according to DSM-III-R criteria (Jensen et al., 1999); however, the endorsement of dysfunction was required to ensure clinical significance and to be more compatible with the spirit of DSM-IV-TR (American Psychiatric Association, 1994). This was measured by using the questions about dysfunction at the end of each diagnostic section in the DICAR. Some subjects in Phase 1 were interviewed 3-weeks postwar and as such the needed 4-weeks duration of PTSD symptoms was not possible to fulfill for all.

The War Events Questionnaire (WEQ) was developed at IDRAAC to evaluate the nature and magnitude of the traumatic war events. It is a face-to-face interview that was administered to adults (in this case the parents) to collect information on the various degrees of destruction of homes or physical injuries to self, family members or others close to the interviewee, in addition to various degrees of witnessing the above events. The interrater reliability $(\kappa)$ of the WEQ ranges from .30 (house damage/self) to .80 (injury/very close person). This instrument was used previously in a large study of the relation of war to depression in adults (Karam et al., 1998) as well as children and adolescents (Karam et al., 2008).

\section{Procedure}

Approval for the study was obtained from the Ethics Review Board of the St. George Hospital University Medical Center. Interviewers were 21 bachelor-level health care workers from the Ministry of Education who received a 4-day training on the in- terview battery. Data collection from students took place at the school after getting informed written consent from parents and assent from children and adolescents. Parents were interviewed separately within their homes or at school. Arrangements were made to interview parents on the same day a child was interviewed and when this was not possible, parent interviews took place within 1-3 days of the child interview. A second wave of meetings and training sessions was carried out with the same selected schools and interviewers 1 year later (Phase 2).

\section{Data Analysis}

War events were summarized as reported in Phase 1 by relation to victim (either self or very close person). Age was dichotomized as children ( $\leq 12$ years old), and adolescent (> 12 years old). MDD, SAD, OAD, and PTSD constituted the prewar disorders analysis along with the presence of any of them reported as any prewar disorder. The Phase 2 subsample was compared to the Phase 1 subsample on age, sex, prewar disorders, psychological stressors, and war exposure. Differences in the proportion were tested using the Pearson $\chi^{2}$ and Fisher exact test when appropriate. Rates for MDD, SAD, OAD, PTSD, and any disorder were tabulated by periods: preexisting (prewar), 3-4 weeks into the cease-fire (Phase 1) and 1 year later (Phase 2). A 2-level analysis was carried out where those free of disorders at 1-month and 1-year postwar were compared to those with disorders at 1-month postwar (nonpersistent and persistent) constituting the first level of analysis. The second level of analysis compared nonpersistent to persistent profiles. Persistence was defined by participants with disorders at 1-month postwar who reported disorders at Phase 2. Nonpersistence was defined by participants with disorders at Phase 1 who did not report disorders at Phase 2. Both levels of analysis were conducted using the Pearson's $\chi^{2}$ or the Fisher exact test if the expected count was small. Similarly, two logistic regression models were built, the first modeling occurrence of disorders versus disorder-free profile, and the second modeling persistent versus nonpersistent profiles. Variables were considered in the models according to their contribution to the model (i.e., $p$-value) and possible confounding effect. Small sample size dictated a limited selection of variables in the models. Coefficients generated by the models were exponentiated to calculate odds ratios (ORs), and standard errors (SEs) were used to build 95\% confidence intervals (CIs). All analyses were carried at the .05 significance level. The software used was SAS Version 9.1.

\section{Results}

The prevalence of current disorders at Phase 1 ranged from $16.1 \%$ for SAD to $25.9 \%$ for MDD and PTSD; there were $44.1 \%$ with any disorder. At Phase 2 the range was OAD at $0 \%$ to MDD at 5.6\%; $9.2 \%$ having any disorder (see Table 2). In Phase 1 , comorbidity rates among those with disorders were as follows: two disorders $26.4 \%$, three disorders $24.1 \%$, four 
Table 2

Prevalence of Mental Disorders by Study Period

Time period

\begin{tabular}{|c|c|c|c|c|c|c|}
\hline \multirow[b]{3}{*}{ Variable } & & & \multicolumn{4}{|c|}{ Postwar } \\
\hline & \multicolumn{2}{|c|}{ Prewar } & \multicolumn{2}{|c|}{1 month } & \multicolumn{2}{|c|}{1 year } \\
\hline & $n$ & $\%$ & $n$ & $\%$ & $n$ & $\%$ \\
\hline MDD & 5 & 3.5 & 37 & 25.9 & 8 & 5.6 \\
\hline SAD & 5 & 3.5 & 23 & 16.1 & 6 & 4.2 \\
\hline OAD & 10 & 7.0 & 40 & 28.0 & 0 & - \\
\hline PTSD & 3 & 2.1 & 37 & 25.9 & 2 & 1.4 \\
\hline Any & 18 & 12.7 & 63 & 44.1 & 13 & 9.2 \\
\hline
\end{tabular}

Note. $N=143 . \mathrm{MDD}=$ major depressive disorder; $\mathrm{SAD}=$ separation anxiety disorder; $\mathrm{OAD}=$ overanxious disorder; PTSD $=$ posttraumatic stress disorder.

disorders $8.6 \%$. In Phase 2, 23.0\% had two disorders, and none had three or more disorders.

Examining the course of disorders over 1 year revealed the following: Of those who had any Phase 1 disorder, $17.4 \%$ (11/63) still had a disorder at Phase 2. Those who were free of disorders at Phase 1 continued to be free of disorders at Phase 2 except for $2.5 \%$ (2/80) who had MDD at Phase 2 (Figure 1).
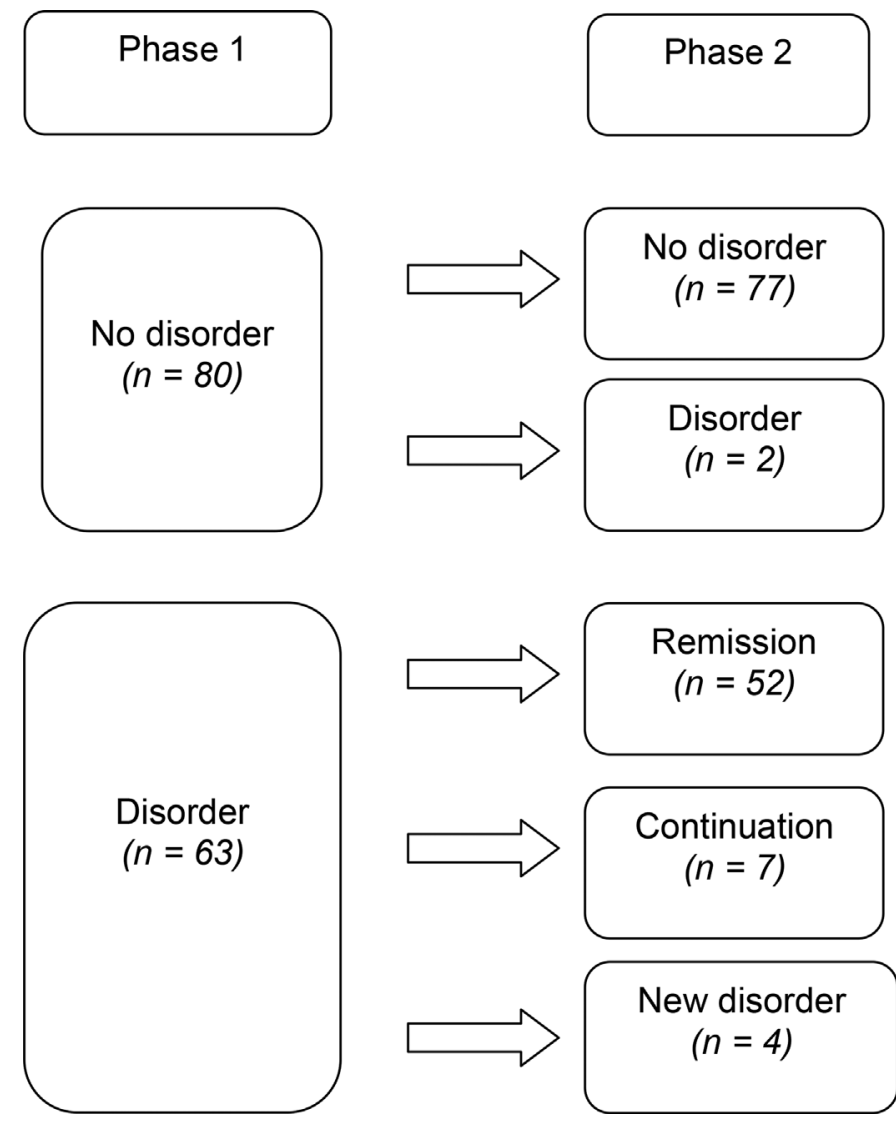

Figure 1. Course of disorders from Phase 1 to Phase 2.
In the multivariate analyses conducted at Phase 1, MDD was predicted by war exposure and prewar OAD. SAD was predicted by younger age, war exposure, prewar SAD, prewar PTSD, and chronic illness. OAD was predicted by prewar OAD, financial problems, chronic illness, fear of being beaten, and bereavement. PTSD was predicted by prewar SAD, prewar OAD, financial problems, and fear of being beaten. Finally, having any disorder was predicted by younger age, having any prewar disorder, chronic illness, and fear by being beaten.

Given the small number of children and adolescents within each diagnostic category in Phase 2, all subsequent analyses were conducted to determine associations of covariates with occurrence of any disorder at Phase 1 and persistence of any disorder at Phase 2.

Children younger than 12 were less likely to have had a disorder at Phase 1 than adolescents (see Table 3). Sex was unrelated to occurrence of disorders. Prewar SAD, OAD, and any disorder were significantly associated with occurrence of disorders at Phase 1. Four of the psychosocial stressors were significantly related to occurrence of disorders at Phase 1: family quarrels, financial problems, fear of being beaten, and a family member having been beaten. Witnessing any war event was significantly associated with occurrence of disorder at Phase 1 and so was witnessing a close person sustaining a personal injury. Persistence of disorders at Phase 2 was associated with witnessing any war event and witnessing a close person sustaining a personal injury. Age, sex, prewar disorders, and psychosocial stressors were not statistically significantly associated with persistence of disorders at Phase 2.

In logistic regression models that included age, prewar disorders, psychosocial stressors, and war exposure, the covariates found to be significantly related to occurrence were adolescence $(O R=3.90,95 \%$ CI $[1.7,10.0])$, having any prewar disorder $(O R=28.60,95 \%$ CI $[3.4,242.8])$, financial problems $(O R=$ $3.60,95 \%$ CI $[1.5,8.30])$, fear of being beaten $(O R=2.50$, $95 \% \mathrm{CI}[1.01,6.4])$, and witnessing any war event $(O R=3.90$, $95 \%$ CI $[1.2,14.2])$. Variables found to be related to persistence of disorders at Phase 2 were having any prewar disorder $(O R=6.20,95 \%$ CI $[1.0,38.53]$ borderline significance $)$ and witnessing any war event $(O R=14.30,95 \%$ CI [2.20, 91.44], see Table 4).

\section{Discussion}

Our study found that although almost half of children and adolescent met criteria for MDD, SAD, OAD, or PTSD after war, only $9.0 \%$ continued to meet full criteria a year later. The occurrence of these disorders after war was associated with older age, prewar disorders, financial problems, fear of violence within the home, and witnessing of war events. Persistence of disorders 1 year later, however, was associated only with prewar disorders and witnessing of war events. These findings are similar to what was found in an independent sample of Lebanese children who had participated in postwar controlled classroom-based 
Table 3

Associated Variables and Tests of Difference by Disorder Category From Combination of Status at Phase 1 and Phase 2

\begin{tabular}{|c|c|c|c|c|c|c|c|c|c|c|}
\hline \multirow[b]{5}{*}{ Variable } & \multicolumn{8}{|c|}{ Phase 1 disorder } & \multirow{5}{*}{$\begin{array}{c}\text { OCCUR }^{\mathrm{a}} \\
p\end{array}$} & \multirow{5}{*}{$\begin{array}{c}\text { PERSIST }^{\mathrm{b}} \\
p\end{array}$} \\
\hline & \multicolumn{2}{|c|}{ No } & \multicolumn{6}{|c|}{ Yes } & & \\
\hline & \multicolumn{8}{|c|}{ Phase 2 disorder } & & \\
\hline & \multicolumn{2}{|c|}{ No $(n=77)$} & \multicolumn{2}{|c|}{ Yes and no $(n=63)$} & \multicolumn{2}{|c|}{ No $(n=52)$} & \multicolumn{2}{|c|}{ Yes $(n=11)$} & & \\
\hline & $n$ & $\%$ & $n$ & $\%$ & $n$ & $\%$ & $n$ & $\%$ & & \\
\hline \multicolumn{11}{|l|}{ Sex } \\
\hline Female & 37 & 48.1 & 35 & 55.6 & 29 & 55.8 & 6 & 54.6 & \multirow[t]{2}{*}{.38} & \multirow[t]{2}{*}{$.99^{\mathrm{c}}$} \\
\hline Male & 40 & 51.9 & 28 & 44.4 & 23 & 44.2 & 5 & 44.5 & & \\
\hline \multicolumn{11}{|l|}{ Age } \\
\hline$\leq 12$ years & 56 & 72.7 & 33 & 52.9 & 26 & 50.0 & 7 & 63.6 & \multirow[t]{2}{*}{.01} & \multirow[t]{2}{*}{.41} \\
\hline$>12$ years & 21 & 27.3 & 30 & 47.6 & 26 & 50.0 & 4 & 36.4 & & \\
\hline \multicolumn{11}{|l|}{ Prewar disorder } \\
\hline MDD & 1 & 1.3 & 4 & 6.4 & 2 & 3.9 & 2 & 18.2 & $.18^{\mathrm{c}}$ & $.14^{\mathrm{c}}$ \\
\hline SAD & 0 & 0.0 & 5 & 7.9 & 4 & 7.7 & 1 & 9.1 & $.02^{\mathrm{c}}$ & $.99^{\mathrm{c}}$ \\
\hline $\mathrm{OAD}$ & 0 & 0.0 & 10 & 15.9 & 7 & 13.5 & 3 & 27.3 & $<.01^{\mathrm{c}}$ & $.36^{\mathrm{c}}$ \\
\hline PTSD & 0 & 0.0 & 3 & 4.8 & 1 & 1.9 & 2 & 18.2 & $.09^{\mathrm{c}}$ & $.08^{\mathrm{c}}$ \\
\hline Any & 1 & 1.3 & 17 & 26.0 & 12 & 23.1 & 5 & 45.5 & $<.01$ & $.15^{\mathrm{c}}$ \\
\hline \multicolumn{11}{|l|}{ Stressors } \\
\hline Family quarrels & 21 & 27.3 & 37 & 58.7 & 30 & 57.7 & 7 & 63.6 & $<.01$ & $.99^{\mathrm{c}}$ \\
\hline Financial problems & 27 & 35.1 & 43 & 68.3 & 33 & 63.5 & 10 & 90.9 & $<.01$ & $.15^{\mathrm{c}}$ \\
\hline Fear of being beaten & 24 & 31.2 & 33 & 52.4 & 25 & 48.1 & 8 & 72.7 & .01 & $.19^{\mathrm{c}}$ \\
\hline Family member beaten & 12 & 15.6 & 21 & 33.3 & 17 & 32.7 & 4 & 36.4 & .01 & $.99^{\mathrm{c}}$ \\
\hline \multicolumn{11}{|l|}{ War exposure } \\
\hline Any event & 5 & 6.5 & 12 & 19.1 & 6 & 11.5 & 6 & 54.6 & .02 & $<.01^{\mathrm{c}}$ \\
\hline Close person injured & 0 & 0.0 & 4 & 6.4 & 1 & 1.9 & 3 & 27.3 & $.04^{\mathrm{c}}$ & $.02^{\mathrm{c}}$ \\
\hline
\end{tabular}

Note . OCCUR = occurrence; PERSIST = persistence; MDD = major depressive disorder; $\mathrm{SAD}=$ separation anxiety disorder; OAD $=$ overanxious disorder; PTSD $=$ posttraumatic stress disorder.

${ }^{a}$ Comparison of the 77 participants with no disorder to the 63 with disorder. Total of those with an occurrence $n=63$. ${ }^{b}$ Comparison of the 52 nonpersistent to the 11 persistent participants. ${ }^{\mathrm{c}}$ Fisher exact test used due to small cell counts.

intervention (Karam et al., 2008), as well as in Croatia and Rwanda where eye-witnessing of war events was one of the most important predictors of PTSD (Kuterovac-Jagodic, 2003; Neugebauer et al., 2009).
The findings of a high prevalence of both depression and anxiety disorders after war replicates what we found in another independent sample of Lebanese children as well as what was reported in a community sample of children in the aftermath

Table 4

Logistic Regressions for Disorder at One Month Postwar and Persistence at One Year

\begin{tabular}{|c|c|c|c|c|c|c|}
\hline \multirow[b]{2}{*}{ Variable } & \multicolumn{3}{|c|}{ Disorder at 1 month } & \multicolumn{3}{|c|}{ Persistence at 1 year } \\
\hline & $O R$ & $95 \% \mathrm{CI}$ & $p$ & $O R$ & $95 \% \mathrm{CI}$ & $p$ \\
\hline Age $>12$ years (reference $=\leq 12$ years) & 3.9 & {$[1.7,10.03]$} & .004 & 1.0 & {$[0.2,5.49]$} & .962 \\
\hline Prewar disorder (reference $=$ none $)$ & 28.6 & {$[3.4,242.8]$} & .002 & 6.2 & {$[1.0,38.53]$} & .051 \\
\hline Financial problems $($ reference $=$ none $)$ & 3.6 & {$[1.5,8.30]$} & .003 & 3.6 & {$[0.3,38.76]$} & .299 \\
\hline Fear of being beaten (reference $=$ none $)$ & 2.5 & {$[1.0,6.35]$} & .047 & 1.9 & {$[0.3,11.73]$} & .483 \\
\hline Witnessing war event (reference $=$ none $)$ & 3.9 & {$[1.1,14.20]$} & .041 & 14.3 & {$[2.2,91.44]$} & .005 \\
\hline
\end{tabular}

Note. $N=143 . O R=$ odds ratio; $\mathrm{CI}=$ confidence interval. 
of the September 11 attacks in New York City (Hoven et al., 2005).

This pattern of a surge in the prevalence of disorders after war and their subsequent decline is compatible with a diathesisstress model through which children and adolescents with specific vulnerabilities such as prewar disorders and psychosocial stressors go on to develop a persistent distress or a fear response after war trauma. However, the lower prevalence of disorders at Phase 2 does not imply freedom from symptoms given that children and adolescents who did not meet full criteria for one of the disorders 1 year after war may have had clinically significant subthreshold symptoms (Karam, Al Atrash, Saliba, Melhem, \& Howard, 1999). Indeed, in an earlier unpublished analysis of data from our study, $7.7 \%$ of subjects met criteria for two out of the three clusters of PTSD (reexperiencing, avoidance, and arousal) in Phase 2 as opposed to $1.4 \%$ meeting full PTSD criteria. Students with subthreshold PTSD at Phase 1 had similar rates of comorbidity and war exposure to those meeting full criteria.

The decline in the prevalence of PTSD is similar to that reported in other prospective studies of children and adolescents exposed to war (Kuterovac-Jagodic, 2003; Schwarzwald et al., 1994; Thabet \& Vostanis, 2000). Possible explanations for the decrease in prevalence in disorders may have to do with their natural course. In studies reporting on referred and nonreferred children and adolescents with MDD, the mean duration of a depressive episode was 9-10 months (Birmaher, Arbelaez, \& Brent, 2002; Carrion, Weems, Ray, \& Reiss, 2002), which is less than the follow-up period of 1 year in our study. Similarly, for SAD and OAD, high rates of recovery $(95.7 \%$ and $80 \%$, respectively) were reported over 3-4 years (Lewinsohn, Clarke, Seeley, \& Rhode, 1994). Moreover, although students in our sample did not receive any psychological treatment to our knowledge, we cannot rule this out with absolute certainty. Although we did not measure social support in this study, there was an outpouring of financial and moral support to the villages affected by the war. This social support could have mitigated against the persistence of symptoms in the affected children (Becker, Weine, Vojvoda, \& McGlashan, 1999; Galante \& Foa, 1986; Last, Perrin, Hersen, \& Kazdin, 1996). Indeed, social support was one of the main factors contributing to positive adjustment in a prospective study of child soldiers in Sierra Leone (Betancourt, Brennan, Rubin-Smith, Fitzmaurice, \& Gilman, 2010). Additionally, there is a small body of literature finding that the children exposed to shelling show higher levels of patriotism than unexposed children and that the prevalent political climate and/or children's political commitment could protect them against psychopathology in comparison to less politically committed children (Muldoon \& Wilson, 2001; Punamaki, 1996; Servan-Schreiber, Lelin, \& Birmaher, 1998; Ziv, Kruglanski, \& Shulman, 1974). These factors may have conceivably contributed further to the attenuation of disorders over time.

One of the strengths in our study is the inclusion of parents as informants in the DICA-R for diagnosis and impairment questions. Most prospective studies of children and trauma (including war) have used children as the only informants. Although it is commonly held that children and adolescents are better informants than their parents regarding internalizing disorders, this issue is far from settled (Laor et al., 2006). Jensen found (Jensen et al., 1999) that parents and children equally identify discrepant cases of anxiety disorders with the authors stating that it is risky to discard information from either informant without sacrificing a significant proportion of cases. Similarly, Grills and Ollendick (2003) found that agreement for anxiety disorders was higher between parent and consensus diagnosis than that between child and consensus diagnosis. In a study of PTSD in children exposed to motor vehicle accidents, there were discrepancies between parental and child reports of both acute stress disorder and PTSD symptoms (Meiser-Stedman, Smith, Glucksman, Yule, \& Dalgleish, 2008).

Our findings on the relation between pre- and postwar disorders support similar findings from studies of natural disasters where lifetime anxiety disorders $(\mathrm{SAD}, \mathrm{OAD})$ predicted postearthquake PTSD and MDD (Asarnow et al., 1999), where having received mental health services before the Southeast Asia tsunami predicted PTSD scores after the tsunami (Jensen et al., 2009) and predisaster anxiety was significantly related to PTSD after Hurricane Andrew (La Greca, Silverman, \& Wasserstein, 1998) and Hurricane Katrina (Weems et al., 2007).

Although it is well known that exposure to family violence such as physical abuse could itself lead to the development of PTSD in children, the coexistence of exposure to both family violence and war in children has received very little attention so far. Catani, Jacob, Schauer, Kohila, and Neuner (2008) reported that both family violence and severity of exposure to the tsunami in Sri Lanka predicted PTSD symptoms. We had similarly found in an independent sample of Lebanese children and adolescents that exposure to family violence (family quarrels and fear of being beaten at home) was associated with persistence of MDD, SAD, and PTSD 1 year after war (Karam et al., 2008).

Findings from this study need to be interpreted in light of a few limitations. The sample size at Phase 2 was too small to allow examination of each disorder alone when several variables had to be studied independently. This restricted our ability to establish statistically significant relationships and to conduct multivariate analyses for each disorder at Phase 2. Scarce resources were the main reason behind this relatively limited sample size. Second, only parents were informants on war events in the WEQ. Although we suspect that in Lebanon, where families are tightly knit, parents would know about their children's exposure to war events, it is conceivable that children may have experienced particular events without their parents' knowledge. This may partially explain the relatively low number of children who directly witnessed war events. Third, a minority of children did not meet the full duration of PTSD criteria in Phase 1 as they were interviewed 3 weeks after the war. Fourth, though we do not have a reason to doubt the representativeness of our sample, 
we cannot confirm this in all certainty as there is no national census data from 1996 with age and sex distributions. Fifth, reporting bias favoring greater recall of symptoms at Phase 1 may have occurred since war exposure was measured only at Phase 1. Moreover, because we did not measure stressors at Phase 2, some stressors may have occurred during the year between Phase 1 and Phase 2. Taken together, these limitations could have biased results in terms of underestimating the true degree of war exposure children experienced, underreporting of disorders at Phase 2, and underpowering the statistical analyses given the smaller sample size at Phase 2.

This study is one of the very few prospective epidemiologic studies to examine mental health consequences of war trauma in nonrefugee children and adolescents in their original countries. Its strength lies not only in its epidemiologic design, but also in measuring multiple adversities (other than war) and outcomes other than PTSD, including depression and anxiety disorders using multiple informants and structured interviews. From a public health perspective, our findings have implications for screening for disorders other than PTSD as well as for detection of at risk cases by identifying adolescents exposed to family violence, those with prewar mental disorders and those who directly witnessed war events in order to target them for specific interventions.

\section{References}

American Psychiatric Association. (1987). Diagnostic and statistical manual of mental disorders ( ${ }^{\text {rd }}$ ed., text rev.). Washington, DC: Author.

American Psychiatric Association. (1994). Diagnostic and statistical manual of mental disorders, $\left(4^{\text {th }}\right.$ ed., text rev.). Washington, DC: Author.

Asarnow, J., Glynn, S., Pynoos, R. S., Nahum, J., Guthrie, D., Contwell, D. P., \& Franklin, B. (1999). When the earth stops shaking: Earthquake sequelae among children diagnosed for pre-earthquake psychopathology. Journal of American Academy of Child and Adolescent Psychiatry, 38, 1016-1023. doi:10.1097/00004583-199908000-00018

Becker, D. F., Weine, S. M., Vojvoda, D., \& McGlashan, T. H. (1999). Case series: PTSD symptoms in adolescent survivors of "ethnic cleaning". Results from a 1-year follow-up study. Journal of American Academy of Child and Adolescent Psychiatry, 38, 775-781. doi:10.1097/00004583-19990600000027

Betancourt, T. S., Brennan, R. T., Rubin-Smith, J., Fitzmaurice, G. M., \& Gilman, S. E. (2010). Sierra Leone's former child soldiers: A longitudinal study of risk, protective factors, and mental health. Journal of American Academy of Child and Adolescent Psychiatry, 49, 606-615. doi:10.1016/j.jaac.2010.03.008

Birmaher, B., Arbelaez, C., \& Brent D. (2002). Course and outcome of child and adolescent major depressive disorder. Child and Adolescent Psychiatric Clinics of North America, 11, 619-637. doi:10.1016/S1056-4993(02)000111

Bolton, D., Hill, J., O'Ryan, D., Udwin, O., Boyle, S., \& Yule, W. (2004). Longterm effects of psychological trauma on psychosocial functioning. Journal of Child Psychology and Psychiatry, 45, 1007-1014. doi:10.1111/j.14697610.2004.t01-1-00292.x

Carrion, V. G., Weems C. F., Ray R., \& Reiss, A. L. (2002). Toward an empirical definition of pediatric PTSD: The phenomenology of PTSD symptoms in youth. Journal of American Academy of Child and Adolescent Psychiatry, 41, 166-173. doi:10.1097/00004583-200202000-00010
Catani, C., Jacob, N., Schauer, E., Kohila, M., \& Neuner, F. (2008). Family violence, war, and natural disasters: A study of the effect of extreme stress on children's mental health in Sri Lanka. BMC Psychiatry, 8, 33. doi:10.1186/1471-244X-8-33

Cordahi, C., Karam, E. G., Nehmé, G., Fayyad, J., Melhem, N., \& Rashidi, N. (2002). Les orphelins de la guerre expérience Libanaise et méthodologie d'un suivi prospectif. [The experience of orphans of the Lebanon war and methodology for future prospects.] Stress et Trauma, 2, 1-9.

Dyregrov, A., Gjestad, R., \& Raundalen, M. (2002). Children exposed to warfare: A longitudinal study. Journal of Trauma and Stress, 15, 59-68. doi:10.1023/a:1014335312219

Galante, R., \& Foa, D. (1986). An Epidemiological study of psychic trauma and treatment effectiveness for children after a natural disaster. Journal of American Academy of Child and Adolescent Psychiatry, 25, 357-363. doi:10.1016/S0002-7138(09)60257-0

Goenjian, A. K., Walling, D., Steinberg, A. M., Karayan, I., Najarian, L. M., \& Pynoos, R. (2004). A prospective study of posttraumatic stress and depressive reactions among treated and untreated adolescents 5 years after a catastrophic disaster. American Journal of Psychiatry, 162, 2302-2308. doi:10.1016/j.jad.2012.02.015

Green, B. L., Grace, M. C., Vary, M. G., Kramer, T. C., Gleser, G. C., \& Leonard, A. C. (1994). Children of disaster in the second decade: A seventeen-year follow-up of Buffalo Creek survivors. Journal of American Academy of Child and Adolescent Psychiatry, 33, 71-79. doi:10.1097/00004583-199401000-00011

Grills, A., \& Ollendick, T. H. (2003). Multiple informant agreement and the anxiety disorders interview schedule for parents and children. Journal of American Academy of Child and Adolescent Psychiatry, 42, 30-40. doi:10.1097/00004583-200301000-00008

Hadi, F., Labre, M. M., \& Spitzer, S. (2006). Gulf war-related trauma and psychological distress of Kuwaiti children and their mothers. Journal of Trauma and Stress, 19, 653-662. doi:10.1002/jts.20153

Hoven, C. W., Duarte, C. S., Lucas, C. P., Wu, P., Mandell, D. J., Goodwin, .. . Susser, E. (2005). Psychopathology among New York City public school children 6 months after September 11. Archives General Psychiatry, 62, 545-551. doi:10.1001/archpsyc.62.5.545

Jensen, P. S., Rubio-Stipec, M., Canino, G., Bird, H. R., Dulcan, M. K., Schwab-Stone, M. E., \& Lahey B. B. (1999). Parent and child contributions to diagnosis of mental disorder: Are both informants always necessary? Journal of American Academy of Child and Adolescent Psychiatry, 38, 1569-1579. doi:10.1097/00004583-199912000-00019

Jensen, T. K., Dyb, G., \& Nygaard, E. (2009). A longitudinal study of posttraumatic stress reactions in Norwegian children and adolescents exposed to the 2004 tsunami. Archives of Pediatric and Adolescent Medicine, 163, 856-861. doi: 10.1001/archpediatrics.2009.151

Karam, E. G., Al Atrash, R., Saliba, S., Melhem, N. \& Howard, D. (1999). The war events questionnaire. Social Psychiatry Psychiatric Epidemiology, 34, 265-274. doi: 10.1007/s001270050143

Karam, E. G., Fayyad, J., Nasser Karam, A., Cordahi Tabet, C., Melhem, N., Mneimneh, Z., \& Dimassi, H. (2008). Effectiveness and specificity of a classroom-based group intervention in children and adolescents exposed to war in Lebanon. World Psychiatry, 7, 103-109.

Karam, E. G., Howard, D., Shaya, M., Mansour, C., Saliba, S., Karam, A. K., ... Jabbour, J. (1998). Les guerres du Liban: Comorbidité de la dépression et troubles post-traumatiques. [The wars in Lebanon: Comorbitity of depression and posttraumatic stress disorder]. Nervure, 11, 14-17.

Kuterovac-Jagodic, G. (2003). Posttraumatic stress symptoms in Croatian children exposed to war: A prospective study. Journal of Clinical Psychology, 59, 9-25. doi:10.1002/jclp.10114 
La Greca, A. M., Silverman, W. K., Vernberg, E. M., \& Prinstein, M. J. (1996) Symptoms of post-traumatic stress in children after hurricane Andrew: A prospective study. Journal of Consulting and Clinical Psychology, 64, 712723. doi:10.1037/0022-006X.64.4.712

La Greca, A. M., Silverman, W. K., \& Wasserstein, S. B. (1998). Children's predisaster functioning as a predictor of posttraumatic stress following Hurricane Andrew. Journal of Consulting and Clinical Psychology, 66, 883-92. doi:10.1037/0022-006X.66.6.883

Laor, N., Wolmer, L., Alon, M., Siev, J., Samuel, E., \& Toren, P. (2006). Risk and protective factors mediating psychological symptoms and ideological commitment of adolescents facing continuous terrorism. Journal of Nervus and Mental Disease, 194, 279-286. doi:10.1097/01.nmd.0000207364.68064.dc

Laor, N., Wolmer, L., \& Cohen, D. J. (2001). Mothers' functioning and children's symptoms 5 years after a SCUD missile attack. American Journal of Psychiatry, 158, 1020-1026. doi:10.1176/appi.ajp.158.7.1020

Last, C. G., Perrin, S., Hersen, M., \& Kazdin, A. E. (1996). A prospective study of childhood anxiety disorders. Journal of American Academy of Child and Adolescent Psychiatry, 35, 1502-1510. doi:10.1097/00004583-19961100000019

Lewinsohn, P. M., Clarke, G. N., Seeley, J. R., \& Rhode, P. (1994). Major depression in community adolescents: Age at onset, episode duration, and time to recurrence. Journal of American Academy of Child and Adolescent Psychiatry, 33, 809-818. doi: 10.1097/00004583-19940700000006

Lustig, S. L., Kia-Keating, M., Knight, W. G., Geltman, P., Ellis, H., Kinzie, J. D., ... Saxe, G. N. (2004). Review of child and adolescent refugee mental health. Journal of American Academy of Child and Adolescent Psychiatry, 43, 24-36. doi: 10.1097/00004583-200401000-00012

McClellan, J., \& Werry, J. S. (2000). Research Psychiatric Diagnostic Interviews for Children and Adolescents. Journal of American Academy of Child and Adolescent Psychiatry 2000; 39, 19-27. doi:10.1097/00004583200001000-00013

McFarlane, A. C., \& Van Hooff, M. (2009). Impact of childhood exposure to a natural disaster on adult mental health: 20-year longitudinal follow-up study. British Journal of Psychiatry, 195, 142-148. doi:10.1192/bjp.bp.108.054270

Meiser-Stedman, R., Smith, P., Glucksman, E., Yule, W., \& Dalgleish, T. (2008). The posttraumatic stress disorder diagnosis in preschool- and elementary school-age children exposed to motor vehicle accidents. American Journal of Psychiatry, 165, 1326-1337. doi:10.1176/appi.ajp.2008.07081282
Mirza, K. A., Bhadrinath, B. R., Goodyer, I. M., \& Gilmour, C. (1998). Post-traumatic stress disorder in children and adolescents following road traffic accidents. British Journal of Psychiatry, 172, 443-447. doi:10.1192/bjp.172.5.443

Muldoon, O. T., \& Wilson, K. (2001). Ideological commitment, experience of conflict and adjustment in Northern Irish adolescents. Medicine, Conflict and Survival, 17, 112-124. doi:10.1080/13623690108409565

Neugebauer, R., Fisher, P. W., Turner, J. B., Yamabe, S., Sarsfield, J. A., \& Stehling-Ariza, T. (2009). Posttraumatic stress reactions among Rwandan children and adolescents in the early aftermath of genocide. International Journal Epidemiology, 38, 1033-1045. doi:10.1093/ije/dyn375

Punamaki, R. L. (1996). Can ideological commitment protect children's psychological wellbeing in situations of political violence? Child Development, 67, 55-69. doi:10.1111/j.1467-8624.1996.tb01719.x

Schwarzwald, J., Weisenberg, M., Solomon, Z., \& Waysman, M. (1994). Stress reactions of school-age children to the bombardment by SCUD missiles: A 1-year follow-up. Journal of Traumatic Stress, 7, 657-667. doi:10.1007/BF02103013

Servan-Schreiber, D., Lelin, B., \& Birmaher, B. (1998). Prevalence of posttraumatic stress disorder and major depressive disorder in Tibetan refugee children. Journal of American Academy of Child and Adolescent Psychiatry, 37, 874-879. doi:10.1097/00004583-199808000-00018

Shaw, J. A., Applegate, B., \& Schorr, C. (1996). Twenty-one-month followup study of school-age children exposed to Hurricane Andrew. Journal of American Academy of Child and Adolescent Psychiatry, 35, 359-364. doi:10.1097/00004583-199603000-00018

Thabet, A. A., \& Vostanis, P. (2000). Posttraumatic stress disorder reactions in children of war: A longitudinal study. Child Abuse and Neglect, 24, 291-298. doi:10.1016/S0145-2134(99)00127-1

Weems, C. F., Pina, A. A., Costa, N. M., Watts, S. E., Taylor, L. K., \& Cannon, M. F. (2007). Predisaster trait anxiety and negative affect predict posttraumatic stress in youths after hurricane Katrina. Journal of Consulting and Clinical Psychology, 75, 154-159. doi:10.1037/0022-006X.75.1.154

Welner, Z., Reich, W., Herjanic, B., Jung, K. G., \& Amado, H. (1987). Reliability, validity and parent-child agreement studies of the Diagnostic Interview for Children and Adolescents (DICA). Journal of American Academy of Child and Adolescent Psychiatry, 26, 649-653. doi:10.1097/00004583198709000-00007

Ziv, A., Kruglanski, A. W., \& Shulman, S. (1974). Children's psychological reactions to wartime stress. Journal of Personality and Social Psychology, 30, 24-30. doi: 10.1037/h0036611 